\title{
RESEARCH
}

Open Access

\section{Surgical outcomes of decompression alone versus transpedicular screw fixation for upper lumbar disc herniation}

\author{
Ahmed Y. Soliman ${ }^{1 *}$ and Amr Abu Elfadle ${ }^{2}$
}

\begin{abstract}
Background: Surgical outcomes of upper lumbar disc herniations (ULDHs) including T12-L1, L1-L2, and L2-L3 levels are characteristically less favorable and more unpredictable.

Objectives: This study was conducted to compare the surgical outcomes of decompression alone versus decompression combined with transpedicular screw fixation in treating upper lumbar disc herniation.
\end{abstract}

Methods: This retrospective cohort study was carried out at Neurosurgery Departments, Tanta University. The study included 46 patients with a symptomatic high lumbar herniated disc at T12-L1, L1-L2, and L2-L3 levels. The enrolled patients were divided into two groups depending on whether they were operated on via decompression and partial medial facetectomy (group 1, 22 patients) or via the previous maneuver plus transpedicular screw fixation (group 2, 24 patients). All patients were medically evaluated immediately after the operation; then, they were followed up at the 3rd and the 6th months following surgery. Patients' outcomes were assessed by visual analogue score (VAS) and Oswestry Disability Index (ODI) scores.

Results: Median VAS scores in each group revealed significant reduction immediately following surgery and at each of 7 days, 3 months, and 6 months in comparison with the preoperative VAS score $(p<0.001)$. Furthermore, each group showed significant stepwise reduction in the median ODI score at the 3rd and the 6th months postoperative compared to the preoperative ODI score (group $1=68.0,19.0,15.0 ; p<0.001$ and group $2=66.5$, 20.0, 15.0; $p<0.001)$, with no significant differences between both groups $(p>0.05)$.

Conclusions: Both standalone decompression and decompression combined with transpedicular screw fixation revealed comparable favorable outcomes in patients with ULDH.

Keywords: Upper lumbar disc herniation, Laminectomy, Discectomy, Screw fixation, Visual analogue score, Oswestry Disability Index

\footnotetext{
* Correspondence: ahmad.soliman@med.tanta.edu.eg;

ahmadusuf0@yahoo.com

The work was carried out at the Neurosurgery Department, Tanta University

Hospitals, and zip code 31527, Tanta, Egypt.

${ }^{1}$ Neurosurgery Department, Faculty of Medicine, Tanta University|, Tanta

31527, Egypt

Full list of author information is available at the end of the article
}

\section{Springer Open}

(c) The Author(s). 2021 Open Access This article is licensed under a Creative Commons Attribution 4.0 International License, which permits use, sharing, adaptation, distribution and reproduction in any medium or format, as long as you give appropriate credit to the original author(s) and the source, provide a link to the Creative Commons licence, and indicate if changes were made. The images or other third party material in this article are included in the article's Creative Commons licence, unless indicated otherwise in a credit line to the material. If material is not included in the article's Creative Commons licence and your intended use is not permitted by statutory regulation or exceeds the permitted use, you will need to obtain permission directly from the copyright holder. To view a copy of this licence, visit http://creativecommons.org/licenses/by/4.0/. 


\section{Introduction}

Lumbar disc herniation (LDH) is widely known as bulging of the disc material beyond the limit of the intervertebral disc space. It occurs due to degeneration of the intervertebral disc with subsequent prolapse of the nucleus pulposus throughout a defect in the annulus fibrosus [1].

Anatomical classifications of the lumbar disc herniations are either upper or lower ones. The upper herniations are defined as either L1-L2 and L2-L3 only or expanded to include T12-L1, L1-L2, and L2-L3 levels as well [2].

The L1-L2 and L2-L3 levels are less common in comparison to lower lumbar disc herniations. Their incidence has been reported to be $1-2 \%$ of all herniated lumbar discs [3].

There are some unique anatomical characteristics of the upper lumbar disc herniations in comparison to the lower ones. These include narrower spinal canal diameter, shorter lengths of the lamina, and the orientation of facets that is much more parallel to the midsagittal plane [4].

Compromization of multiple nerve roots or even the conus medullaris may be encountered. Therefore, patients develop ill-defined polyradiculopathies with nonspecific neurological presentations. Localized pain and sensory deficits are rarely determined in these cases [5].

Conventional open surgery is considered the gold standard management of upper lumbar disc herniations following conservative treatment failure to alleviate the neurological manifestations [6]. In conventional surgery, extensive resection of the lamina and/or facet joints is performed. The aim is to make a careful and safe access toward the protruded disc and avoid vigorous manipulation over the dura. However, this may result in iatrogenic instability and postoperative back pain [7]. Alternatively, transpedicular fixation has been used by spine surgeons to avoid postoperative instability and guard against the recurrence of the disc herniation [8].

Surgical outcomes of the upper lumbar disc herniations are characteristically less favorable and more unpredictable due to the unique anatomy of this part of the spine $[9,10]$.

Actually, adequate selection of surgical methods in consideration of herniated disc nature such as consistency, direction, and size is necessary to improve surgical outcomes [11].

Considering the unique anatomical and clinical characteristics of upper lumbar disc herniation (ULDH), there is still controversy in the selection of their surgical approach [3]. To our knowledge, there are few reports of comparative studies concerning decompression alone versus fusion surgery for upper lumbar disc herniation. Therefore, the objective of this study was to compare the surgical outcomes of decompression alone versus combined decompression and transpedicular screw fixation in treating upper lumbar disc herniation.

\section{Methods}

\section{Design, setting, and eligibility criteria}

This retrospective cohort study was carried out at the Neurosurgery Departments, Tanta University, during the period between March 2018 and September 2019. The study included 46 patients with a symptomatic high lumbar herniated disc at T12-L1, L1-L2, and L2-L3 levels. Patients with previous spine surgeries, those with associated lower level LDH, and those with discitis and tumors and psychiatric patients were excluded from this study.

Diagnosis was established by clinical manifestations including low back, radicular pain, motor and/or sensory deficit, reflex changes, sphincter dysfunction, and myelopathy signs. In addition, radiographic evaluation by plain X-ray lumbosacral spine dynamic (flexion-extension positions) and antero-posterior films for all patients was performed to evaluate the dynamic motion characteristics for both upper as well as lower lumbar. For all the patients with any grad of lithesis, pars fractures, or facet joint either osteo-arthropathy or asymmetry, fusion will be considered. Moreover, magnetic resonance imaging (MRI) was performed where disc consistency and direction of herniation were reported (Figs. 1 and 3a, b). Magnetic resonance imaging is the gold standard radiological investigation in the diagnosis of ULDH and can exclude any other pathology. However, radiologic findings alone cannot predict the neurological status of the patient. Hence, decision should be based on clinical findings matched with MRI findings as well [4].

\section{Surgical maneuvers and patients' groups}

Following approval from the local ethical committee and Tanta University institutional review board (TuIRB), informed written consent fulfilling the criteria set by the local research ethical committee had to be obtained before surgery. All patients had failed conservative treatment and, subsequently, surgery was indicated. The enrolled patients were divided into two groups depending on whether they were operated on via standard laminectomy (Fig. 2a), hemi-laminectomy (Fig. 3c, d), fenestration, and partial medial facetectomy to get access to the targeted disc with minimal medial traction upon the corresponding root (group 1, 22 patients) or via the previous maneuver plus transpedicular screw fixation (Fig. 2c, d) (group 2, 24 patients). The operation performed was the standard spinal surgery under general anesthesia, in the prone position. The accurate level of the herniated disc was checked by intraoperative fluoroscopy (Fig. 2b, c).

\section{Data collection}

Preoperative data collection included age, sex, and evaluation of the muscle power status, presence of sphincteric 

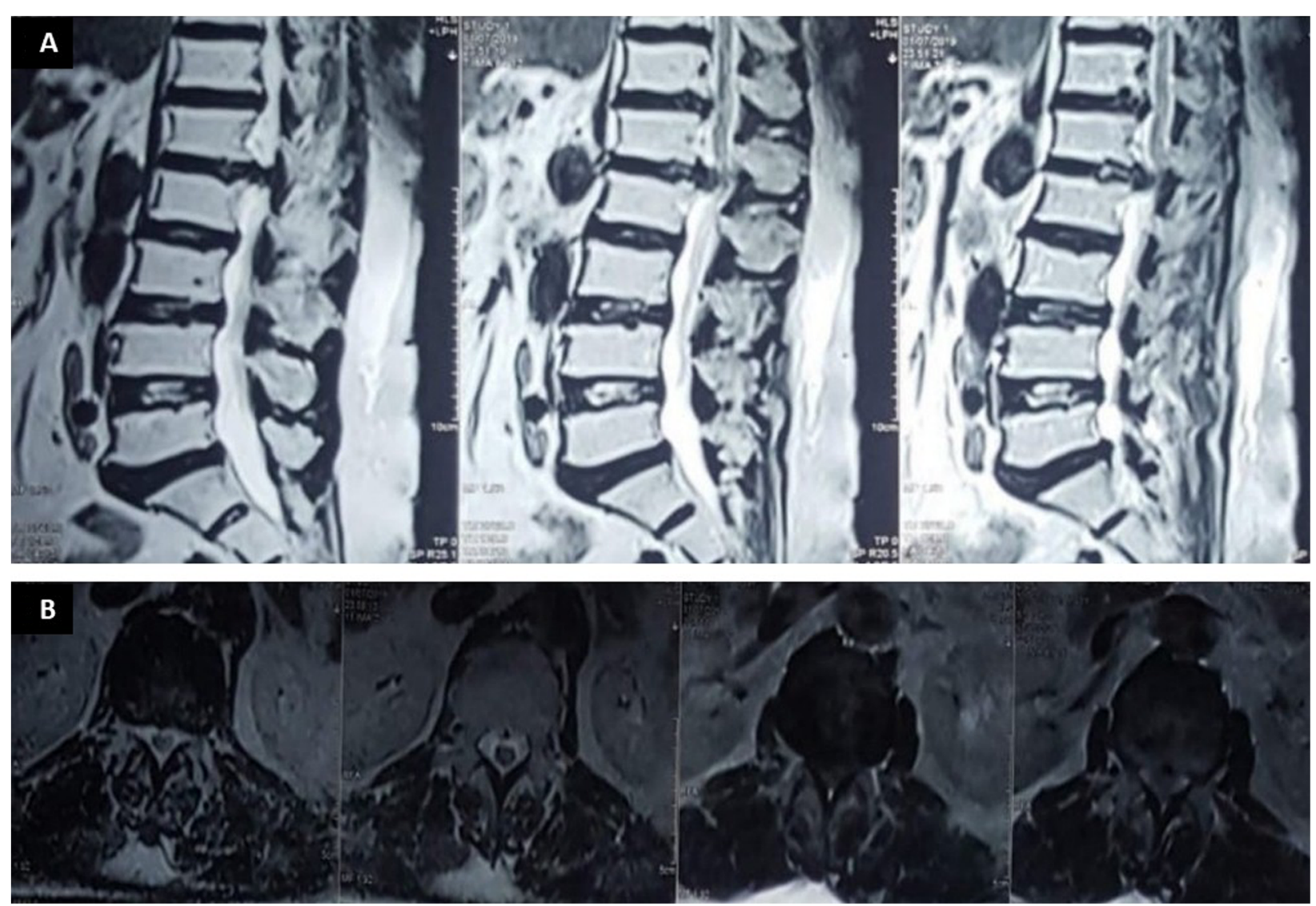

Fig. 1 Preoperative MRI of the lumbosacral spine. a Preoperative T2-weighted Sagittal image of a 42-year-old male presented with bilateral femoralgia and motor deficit for 3 months. b MR of axial image showed L1-L2 sizable herniated disc compromising the conus medullaris

disturbance, visual analogue score (VAS) for pain assessment, and Oswestry Disability Index (ODI) as a functional outcome score.

All patients were medically evaluated immediately after the operation; then, they were followed up through a postoperative visit to the outpatient clinic at the 3rd and the 6th months following surgery. Postoperative data included both clinical evaluation and radiographic imaging. Patients' outcomes were assessed by VAS and ODI scores. Regarding VAS, it was recorded immediately postoperative, at 7 days, and at 3rd and 6th months after the operation, whereas the ODI score was calculated at the 3rd and 6th months. Additionally, postoperative sphincteric condition and improvement of the motor power, amount of blood loss, and operative time were recorded.

ODI is one of the principal condition-specific outcome measures used in the management of spinal disorders. ODI contains 10 questions on the limitation of activities of daily living. Each variable is rated on a 0-5-point scale, summarized and converted into a percentage score, ranging from 0 to $100(0=$ no disability) [12].

\section{Statistics}

Statistical analysis and presentation of data was conducted using Statistical Package for the Social Sciences (SPSS) version 22 computer program. Categorical data were presented as numbers and percentages. Chi-square and/or Fisher's exact tests as appropriate were applied to investigate the association between categorical variables. For continuous data, they were tested for normality by the Shapiro-Wilk test. For normally distributed data, they were expressed as mean \pm standard deviation and an independent $T$ test was used for comparison between the studied groups. For non-normally distributed continuous data, they were expressed as median and interquartile range (25th-75th percentiles) and the Mann-Whitney $U$ test was used for comparison between the studied groups. For comparison of VAS and ODI scores at different times of follow-up, the Friedman test, followed by the Wilcoxonsigned rank test, was applied. The level of statistical significance was considered at $p<0.05$.

\section{Results}

The present study included 46 patients ( 25 males and 21 females) with a mean age of $40.1 \pm 10.0$ years. There were 


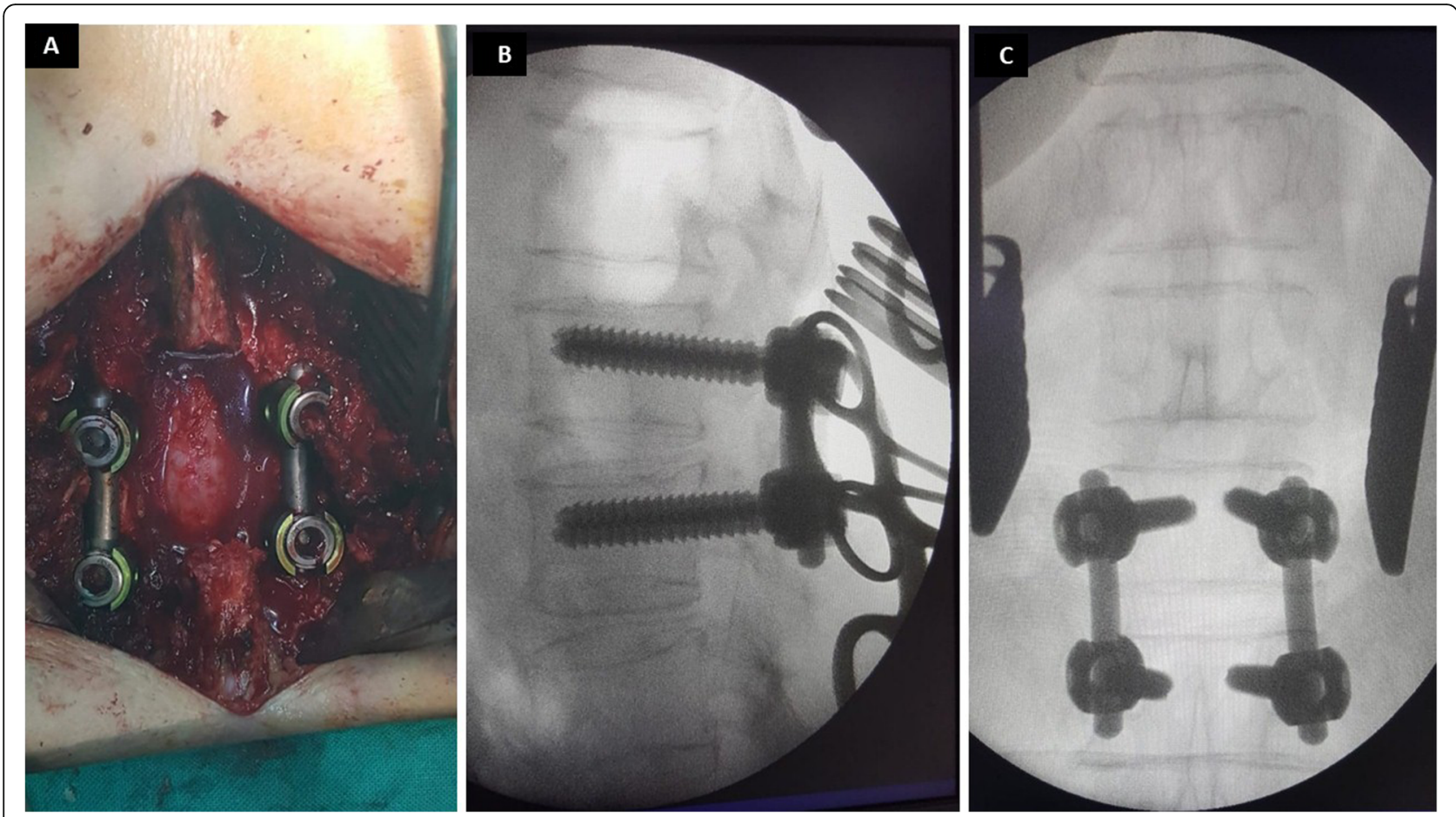

Fig. 2 Intraoperative of the same patient (a) showing the extent of the laminectomy and final transpedicular screw fixation. Intraoperative fluoroscopic images $\mathbf{b}$ lateral view and $\mathbf{c}$ AP view showing the accurate placement of the L1-L2 of the pedicle screw fixation
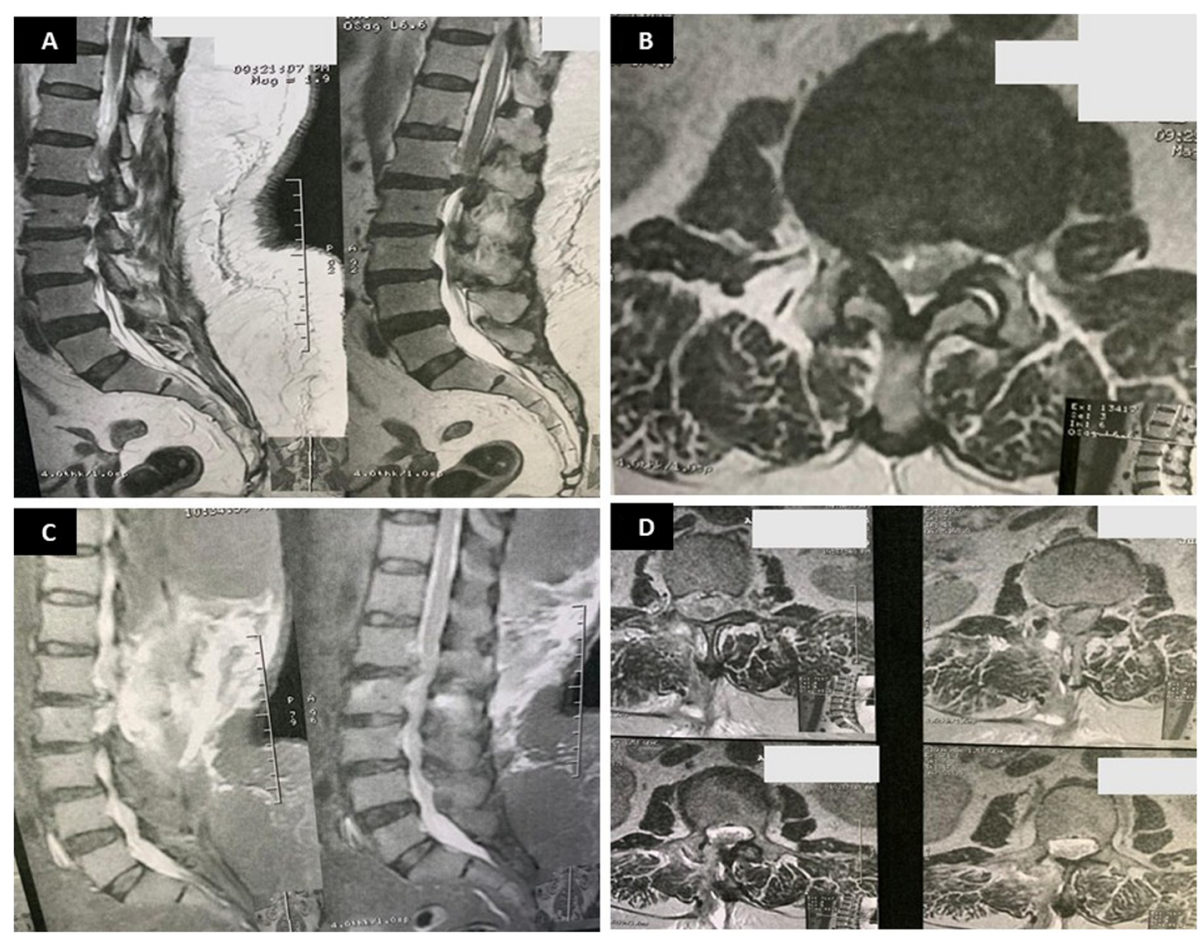

Fig. 3 Preoperative MRI lumbosacral spine of a 67-year-old female presented with right severe femoralgia and motor and visceral deficits for 5 months. a, b Preoperative T2-weighted MR images L1-L2 sizable herniated disc compromising the right root exit foramen. c, $\mathbf{d}$ Postoperative sagittal (c) and axial cuts (d) showing hemi-laminectomy with preservation of the corresponding facet joint and surgical bed with extirpated disc 
Table 1 Patient demographics and baseline characteristics

\begin{tabular}{|c|c|c|c|c|c|c|c|c|}
\hline & & \multicolumn{6}{|c|}{ Groups } & \multirow{3}{*}{$\begin{array}{l}p \\
\text { value }\end{array}$} \\
\hline & & \multicolumn{2}{|c|}{$\begin{array}{l}\text { Group } 1 \\
N=22\end{array}$} & \multicolumn{2}{|c|}{$\begin{array}{l}\text { Group } 2 \\
N=24\end{array}$} & \multicolumn{2}{|c|}{$\begin{array}{l}\text { Total } \\
N=46 \\
\end{array}$} & \\
\hline & & $N$ & $\%$ & $N$ & $\%$ & $N$ & $\%$ & \\
\hline Age (years) & Mean \pm SD & \multicolumn{2}{|c|}{$41.2 \pm 10.5$} & \multicolumn{2}{|c|}{$39.1 \pm 9.7$} & \multicolumn{2}{|c|}{$40.1 \pm 10.0$} & 0.493 \\
\hline \multirow[t]{2}{*}{ Sex } & Female & 10 & 45.5 & 11 & 45.8 & 21 & 45.7 & 0.979 \\
\hline & Male & 12 & 54.5 & 13 & 54.2 & 25 & 54.3 & \\
\hline \multirow[t]{3}{*}{ Level } & T12-L1 & 5 & 22.7 & 5 & 20.8 & 10 & 21.7 & 0.922 \\
\hline & L1-L2 & 7 & 31.8 & 9 & 37.5 & 16 & 34.8 & \\
\hline & L2-L3 & 10 & 45.5 & 10 & 41.7 & 20 & 43.5 & \\
\hline \multirow[t]{2}{*}{ Preoperative muscle weakness } & Absent & 14 & 63.6 & 17 & 70.8 & 31 & 67.4 & 0.603 \\
\hline & Present & 8 & 36.4 & 7 & 29.2 & 15 & 32.6 & \\
\hline \multirow[t]{2}{*}{ Preoperative sphincteric disturbance } & No & 16 & 72.7 & 16 & 66.7 & 32 & 69.6 & 0.655 \\
\hline & Yes & 6 & 27.3 & 8 & 33.3 & 14 & 30.4 & \\
\hline
\end{tabular}

ten (21.7\%) patients with T12-L1 level, 16 (34.8\%) L1-L2 levels, and 20 (43.5\%) L2-L3 level with no significant differences between the studied groups $(p>0.05)$. Furthermore, the frequency of preoperative muscle weakness and sphincteric disturbance was homogenous in both groups with no significant differences $(p>0.05)$ as illustrated in Table 1.
Table 2 shows the comparison of VAS scores in the studied groups. In both groups, the median VAS scores showed improvement postoperatively till the 7th day after the operation. Thereafter, the median VAS score showed an increase at the 3rd and the 6th months after the operation with no significant differences between both groups at all the studied times of follow-up ( $p>$

Table 2 Comparison of preoperative and postoperative VAS scores in the studied groups

\begin{tabular}{|c|c|c|c|c|}
\hline & & \multicolumn{2}{|l|}{ Groups } & \multirow{2}{*}{$\begin{array}{l}\text { Mann-Whitney } U \text { test } \\
p \text { value }\end{array}$} \\
\hline & & $\begin{array}{l}\text { Group } 1 \\
N=22\end{array}$ & $\begin{array}{l}\text { Group } 2 \\
N=24\end{array}$ & \\
\hline \multicolumn{5}{|l|}{ VAS score } \\
\hline \multirow[t]{3}{*}{ Preoperative } & Median & 8.0 & 7.0 & 0.155 \\
\hline & IQR & $7.0-9.0$ & $7.0-8.0$ & \\
\hline & Mean rank & 26.32 & 20.92 & \\
\hline \multirow[t]{3}{*}{ Immediately postoperative } & Median & 2.0 & 2.0 & 0.727 \\
\hline & IQR & $2.0-3.0$ & $2.0-3.0$ & \\
\hline & Mean rank & 24.14 & 22.92 & \\
\hline \multirow[t]{3}{*}{7 days after the operation } & Median & 2.0 & 2.0 & 0.231 \\
\hline & IQR & $2.0-2.0$ & $2.0-2.5$ & \\
\hline & Mean rank & 21.45 & 25.38 & \\
\hline \multirow[t]{3}{*}{3 months after the operation } & Median & 3.0 & 3.0 & 0.880 \\
\hline & IQR & $2.0-3.0$ & $2.0-3.0$ & \\
\hline & Mean rank & 23.77 & 23.25 & \\
\hline \multirow[t]{3}{*}{6 months after the operation } & Median & 3.0 & 2.0 & 0.474 \\
\hline & IQR & $2.0-3.0$ & $2.0-3.0$ & \\
\hline & Mean rank & 24.80 & 22.31 & \\
\hline Friedman test ${ }^{* *}$ & & $<0.001^{*}$ & $<0.001^{*}$ & \\
\hline
\end{tabular}

*Significant at $p<0.05$

**Pairwise comparison of VAS score (Wilcoxon-signed rank) in group 1 revealed significant differences between all-time points ( $p<0.05)$ except immediately postoperative VAS vs 6 months after the operation $(p=0.132)$ and 3 months vs 6 months after the operation $(p=0.564)$, whereas in group 2, there were significant differences between preoperative VAS and each of immediately postoperative VAS, 7 days VAS, 3 months VAS, and 6 months VAS. Additionally, there was a significant difference between 7 days VAS and 3 months VAS $(p<0.05)$. Otherwise, no significant differences between other time points $(p>0.05)$ 
0.05). Moreover, pairwise comparison of median VAS scores in each group revealed a significant reduction immediately after the operation and at each of 7 days, 3 months, and 6 months in comparison with the preoperative VAS score $(p<0.001)$.

Concerning the ODI score, there were no significant differences between both groups before the operation, at the 3rd, or at the 6th months after the operation $(p>0.05)$. Furthermore, each group showed significant stepwise reduction in the median ODI score at the 3rd and the 6th months after the operation compared to the preoperative ODI score (group $1=68.0,19.0,15.0 ; p<$ 0.001 and group $2=66.5,20.0,15.0 ; p<0.001$ ) as illustrated in Fig. 4.

There was complete improvement of the muscle power in $75.0 \%$ and $71.4 \%$ of cases in groups 1 and 2 respectively with no significant differences $(p>0.05)$. Likewise, partial improvement of sphincteric condition was detected in $66.7 \%$ and $62.5 \%$ of patients with preoperative disturbance respectively with no significant difference between the studied groups. Overall patient's satisfaction was $90.9 \%$ in group 1 and $87.5 \%$ in group 2 with no significant differences $(p>0.05)$. Alternatively, the mean amount of blood loss and the mean time of operation was significantly lower in group 1 than in group $2(p<0.001)$ as demonstrated in Table 3.
Tables 4 and 5 show a non-significant association between each of patient's sex and level of the lumbar disc and surgical outcomes represented by improvement of muscle power, urinary bladder condition, and patient's satisfaction $(p>0.05)$.

Minimal non-serious complications were recorded in group 2 in one patient who experienced surgical hematoma at the site of surgery with mild paraparesis, which improved following evacuation of hematoma. Another patient developed early postoperative CSF leak after intraoperative unintended durotomy which stopped and resolved during regular dressing.

\section{Discussion}

This study demonstrated significant improvement in postoperative VAS and ODI scores compared to preoperative scores in patients who underwent either decompression alone or further pedicle screw fixation, with no significant difference between both groups. Furthermore, improvement in muscle power, urinary dysfunction, and patient's satisfaction were comparable in both groups.

The mean age of the studied patients at the time of surgery was $40.1 \pm 10.0$ years. It was previously reported that upper lumbar disc herniations are characterized by

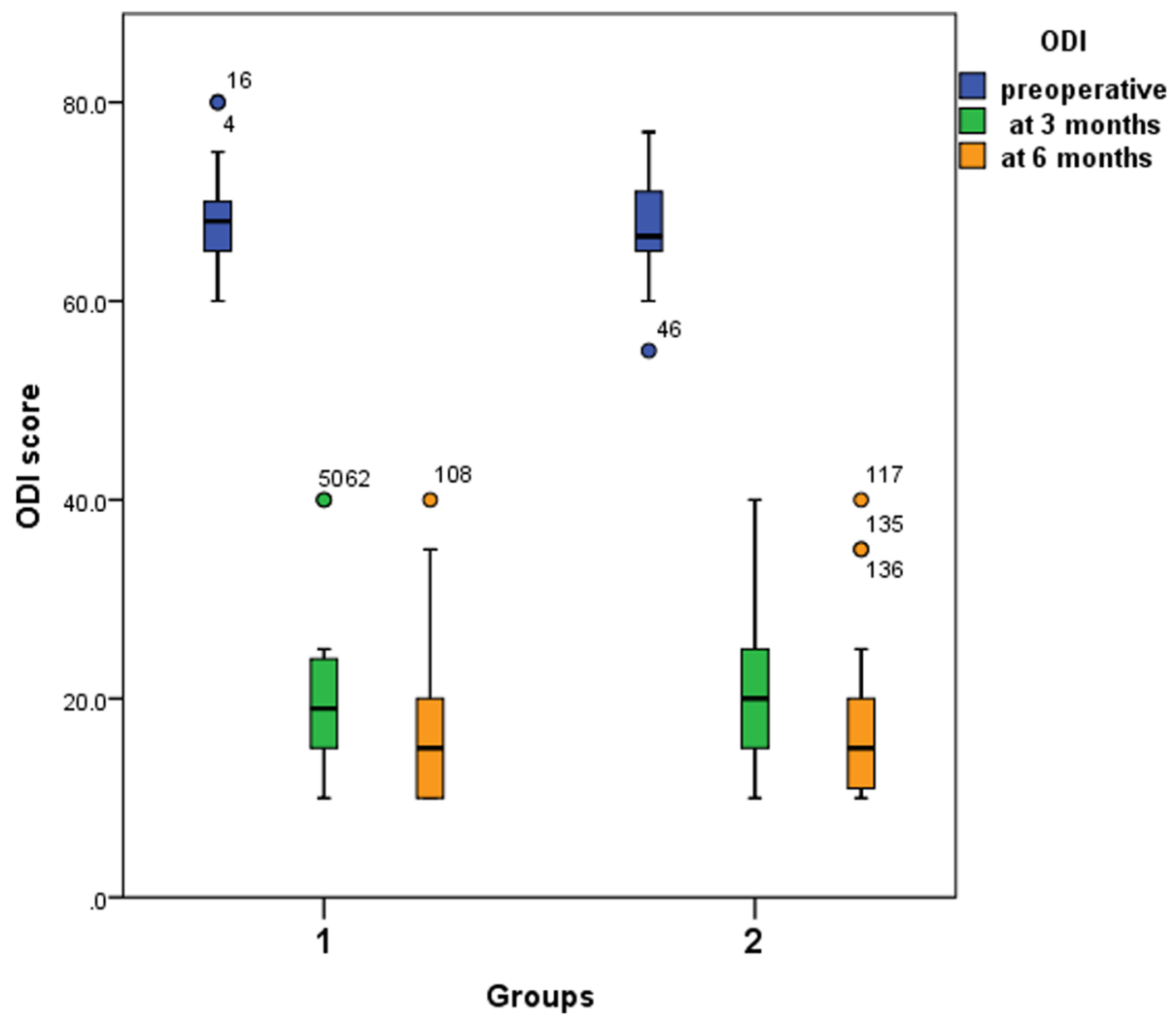

Fig. 4 Comparison of preoperative and postoperative ODI scores in the studied groups 
Table 3 Comparison between the studied groups as regards improvement of the motor power, postoperative sphincteric condition, patients' satisfaction, amount of blood loss, and operation time

\begin{tabular}{|c|c|c|c|c|c|}
\hline & & & \multicolumn{2}{|l|}{ Groups } & \multirow{2}{*}{$\begin{array}{l}p \\
\text { value }\end{array}$} \\
\hline & & & $\begin{array}{l}\text { Group } 1 \\
N=22\end{array}$ & $\begin{array}{l}\text { Group } 2 \\
N=24\end{array}$ & \\
\hline \multirow[t]{4}{*}{ Improvement of the motor power } & Complete improvement & $N$ & 6 & 5 & 0.662 \\
\hline & & $\%$ & 75.0 & 71.4 & \\
\hline & Little improvement & N & 2 & 2 & \\
\hline & & $\%$ & 25.0 & 28.6 & \\
\hline \multirow[t]{4}{*}{ Postoperative sphincteric condition } & Not improved & N & 2 & 3 & 0.657 \\
\hline & & $\%$ & 33.3 & 37.5 & \\
\hline & Partial improvement & $N$ & 4 & 5 & \\
\hline & & $\%$ & 66.7 & 62.5 & \\
\hline \multirow[t]{4}{*}{ Patient satisfaction } & No & N & 2 & 3 & 0.543 \\
\hline & & $\%$ & 9.1 & 12.5 & \\
\hline & Yes & N & 20 & 21 & \\
\hline & & $\%$ & 90.9 & 87.5 & \\
\hline \multirow[t]{2}{*}{ Amount of blood loss (ml) } & Mean & & 205.9 & 283.3 & $<0.001^{*}$ \\
\hline & SD & & 51.3 & 35.9 & \\
\hline \multirow[t]{2}{*}{ Operation time (minutes) } & Mean & & 104.1 & 141.5 & $<0.001^{*}$ \\
\hline & SD & & 11.2 & 8.7 & \\
\hline
\end{tabular}

*Significant at $p<0.05$

being more prevalent among older patients compared to the lower lumbar disc levels $[11,13]$.

The upper lumbar disc herniations in this work were distributed as ten (21.7\%) patients with T12-L1 level, 16 (34.8\%) at L1-L2 level, and $20(43.5 \%)$ at L2-L3 level. Similarly, ElKatany et al. [11] reported higher L2-3 incidence $(60 \%)$ compared to lower (40\%) incidence of L1-2 disc prolapse in their series of upper lumbar disc herniations. In order to reduce motion and stress at the upper lumbar spine, the incidence of disc herniation is much less lower compared to lower lumbar levels as reported by Jha et al. [14].

The neurological manifestations of upper lumbar disc herniations included ill-defined radiculopathies that cannot be clearly categorized into typical muscle group weakness, dermatomal sensory deficits, or reflex deficits. These radiculopathies may be associated with a narrower upper lumbar spinal canal compared to that of the lower spinal canal. So, more than one root could be compromised by a single disc herniation [5].

In this study, patients were presented with back and lower limb pain, and the median preoperative VAS scores were 8.0 and 7.0 in both groups respectively. This coincides with Elqazaz [15] who reported that most patients with ULDH presented with back and buttock pain in addition to leg pain distributions, with the mean values of preoperative back pain by VAS were $7.7 \pm 0.3$. However, it has been stated that localized pain of the

Table 4 Association of sex and surgical outcome in the studied groups

\begin{tabular}{|c|c|c|c|c|c|c|c|c|c|c|c|}
\hline & & \multicolumn{8}{|c|}{ Groups } & \multirow[b]{4}{*}{ P1 value } & \multirow[b]{4}{*}{ P 2 value } \\
\hline & & \multicolumn{4}{|c|}{ Group 1} & \multicolumn{4}{|c|}{ Group 2} & & \\
\hline & & \multicolumn{2}{|c|}{ Female } & \multicolumn{2}{|c|}{ Male } & \multicolumn{2}{|c|}{ Female } & \multicolumn{2}{|c|}{ Male } & & \\
\hline & & $\bar{N}$ & $\%$ & $\bar{N}$ & $\%$ & $\bar{N}$ & $\%$ & $\bar{N}$ & $\%$ & & \\
\hline \multirow[t]{2}{*}{ Improvement of sphincteric condition } & No & 1 & 50.0 & 1 & 25.0 & 0 & 0.0 & 3 & 75.0 & .540 & .071 \\
\hline & Partial & 1 & 50.0 & 3 & 75.0 & 4 & 100.0 & 1 & 25.0 & & \\
\hline \multirow[t]{2}{*}{ Motor power } & Improved & 2 & 66.7 & 4 & 80.0 & 2 & 100.0 & 3 & 60.0 & .673 & .476 \\
\hline & Little improved & 1 & 33.3 & 1 & 20.0 & 0 & 0.0 & 2 & 40.0 & & \\
\hline \multirow[t]{2}{*}{ Patient satisfaction } & No & 1 & 10.0 & 1 & 8.3 & 0 & 0.0 & 3 & 23.1 & .892 & .141 \\
\hline & Yes & 9 & 90.0 & 11 & 91.7 & 11 & 100.0 & 10 & 76.9 & & \\
\hline
\end{tabular}


Table 5 Lumbar disc level and surgical outcome groups

\begin{tabular}{|c|c|c|c|c|c|c|c|c|c|c|c|c|c|c|c|}
\hline & & \multicolumn{12}{|c|}{ Groups } & \multirow[b]{4}{*}{ P1 } & \multirow[b]{4}{*}{ P2 } \\
\hline & & \multicolumn{6}{|c|}{ Group 1} & \multicolumn{6}{|c|}{ Group 2} & & \\
\hline & & \multicolumn{2}{|c|}{ L1-L2 } & \multicolumn{2}{|c|}{ L2-L3 } & \multicolumn{2}{|c|}{ T12-L1 } & \multicolumn{2}{|c|}{ L1-L2 } & \multicolumn{2}{|c|}{ L2-L3 } & \multicolumn{2}{|c|}{ T12-L1 } & & \\
\hline & & $N$ & $\%$ & $N$ & $\%$ & $N$ & $\%$ & $N$ & $\%$ & $N$ & $\%$ & $N$ & $\%$ & & \\
\hline \multirow[t]{2}{*}{ Improvement of sphincteric condition } & No & 0 & 0.0 & 0 & 0.0 & 2 & 100.0 & 2 & 66.7 & 1 & 25.0 & 0 & 0.0 & .200 & .676 \\
\hline & Partial & 2 & 100.0 & 2 & 100.0 & 0 & 0.0 & 1 & 33.3 & 3 & 75.0 & 1 & 100.0 & & \\
\hline \multirow[t]{2}{*}{ Motor power } & Improved & 2 & 100.0 & 3 & 100.0 & 1 & 33.3 & 1 & 50.0 & 1 & 50.0 & 3 & 100.0 & .250 & .778 \\
\hline & Little improved & 0 & 0.0 & 0 & 0.0 & 2 & 66.7 & 1 & 50.0 & 1 & 50.0 & 0 & 0.0 & & \\
\hline \multirow[t]{2}{*}{ Patient satisfaction } & No & 0 & 0.0 & 0 & 0.0 & 2 & 40.0 & 1 & 11.1 & 2 & 20.0 & 0 & 0.0 & .050 & .429 \\
\hline & Yes & 7 & 100.0 & 10 & 100.0 & 3 & 60.0 & 8 & 88.9 & 8 & 80.0 & 5 & 100.0 & & \\
\hline
\end{tabular}

back and lower limbs is rarely demonstrated in ULDH, and it usually precedes the development of myelopathy [16]. Symptomatic herniations present as ill-defined lumbar radiculopathy from both mechanical compression and chemical irritation of the nerve roots [17]. Moreover, it has been reported that pain and/or numbness confined to the thigh area proximal to the knee joint is a characteristic sign of L2 nerve root disturbance, whereas pain distribution along the medial aspect of the knee joint is highly suggestive of L3 nerve root compression [18].

In the current study, about one-third of the patients showed muscle weakness and sphincteric disturbance. Upper lumbar disc herniations are known to be associated with a higher risk of deferent degree of compression upon the conus medullaris leading sometimes to cauda equina syndrome. Bladder dysfunction and muscular weakness of the legs are among its manifestations [19]. Our finding is in agreement with Toubar and El Sawy [20] who reported cauda equina syndrome in 30\% of Egyptian patients with ULDH at their initial presentation.

Diagnosis of ULDH in this study was based on clinical manifestations followed by radiologic investigations including MRI of the lumbar spine. One of the specific clinical tests used in diagnosis was the positive femoral stretch test. It is known as a relatively good diagnostic method in about 84 to $94 \%$ of ULDH. The stretching of the femoral nerve triggers pain because L2, L3, or L4 spinal nerve roots consider the main components of the femoral nerve [21].

Surgical intervention for ULDH should be taken into consideration in cases with refractory complaints [22]. On the other hand, surgical intervention is mandatory and considered as an emergency in case of cauda equina symptoms [23]. According to Satoskar et al. [24], the upper lumbar spine has unique anatomic landmarks that present surgical challenges. Furthermore, there are a variety of techniques besides the conventional laminectomy done for upper LDH [7]. Therefore, the choice of the surgical approach is an important issue while managing patients with upper lumbar herniations, because proper preoperative surgical planning can play the most important role to get a favorable surgical outcome and avoid complications [22].

Many factors play a role in determining the choice of surgical approach. These include disc size, location, extent of calcification, surgeon's experience, degree of spinal cord deformation, and the general medical record of the patient. In cases of L1-L2 and L2-L3 disc herniations, radiologic findings are the outmost important criteria for the selection of the surgical approach [25].

Among the surgical approaches for lumbar disc herniation, open lumbar discectomy (OLD) is considered the gold standard [26]. This technique is much commonly performed because of its good clinical results. In such technique, there is excision of some posterior structures such as lamina, ligament flavum, and facet joints [27]. Thus, it could possibly lead to lumbar instability and iatrogenic injury [28]. Addition of spinal stabilization and fusion by a multitude of instrumentations has been developed [29]. Transpedicular screw fixation has been the treatment of choice for stabilizing segmental instability especially in cases that require wide decompression [30].

In this study, 22 patients (group 1) underwent open discectomy via laminectomy and partial medial facetectomy, and 24 patients (group 2) were operated upon via the previous maneuver plus transpedicular screw fixation to show any differences in surgical outcomes.

There were no significant differences between both groups as regards pain improvement measured by VAS score. Both groups showed significant reduction immediately following surgery and at each of 7 days, 3 months, and 6 months in comparison with the preoperative VAS score $(p<0.001)$. Furthermore, both groups showed good regaining of functional ability; they had significant stepwise reductions in the median ODI scores at the 3rd and the 6th months following surgery compared to the preoperative ODI score with no significant 
differences between both groups. Subjective evaluation of patient's satisfaction was comparable in group 1 (90.9\%) and group 2 (87.5\%). Compared to these findings, Lin et al. [31] have recently reported a greater satisfactory rate $(93.8 \%)$ in series of 16 patients who were operated via transpedicular pedicle screws and interbody fusion with a cage compared to decompression alone (66.7\%). Follow-up of their patients also revealed better functional outcomes (ODI score) at 3 months in the fusion group compared to the decompression group. The addition of interbody fusion with a cage to transpedicular pedicle screw fixation might explain the reported better functional outcomes. However, Lin et al. [31] agree with our findings in the presence of non-significant differences between fusion and decompression groups as regards VAS score, improvement of muscle power, and bladder dysfunction.

An earlier case series of nine patients surgically treated for upper LDH via discectomy through an anterior approach was reported. Four patients of them underwent additional spinal instrumentation using the Kaneda device and Z-plate system. All patients showed improvement of all clinical manifestations [32].

It seems that addition of pedicle screw fixation did not improve the outcomes of ULDH patients. Moreover, our findings revealed significantly lower mean time of the operation and the mean amount of blood loss in patients who underwent decompression alone. The choice of screw fixation is important if a wide posterior laminectomy is performed to decompress the neural structures; this may lead to disruption of the normal anatomy and mechanics of the spinal column resulting in instability, which can lead to surgical failure. In such cases, spinal fusion guards against the possible instability and adds immediate immobilization of the spinal segment, which can improve the axial pain as well as radiculopathy [7, 33]. However, the higher incidence of adjacent segment degeneration, higher costs, and higher complication rates should be taken into consideration [34].

All patients in this study showed significant improvement of postoperative pain, function, muscle power, and urinary incontinence compared to the preoperative conditions. These favorable outcomes of ULDH are in agreement with Sanderson et al. [9] who showed improvements of preoperative pain following microdiscectomies of L1-L2 and L2-L3 disc herniations in $60 \%$ of patients. Similarly, Kim et al. [5] detected relieve of preoperative manifestations in $80 \%$ of cases of ULDH operated via decompression surgery by conventional laminectomy or a posterior transdural approach. Furthermore, transfacet discectomy with pedicle screw fixation in twenty patients diagnosed with herniated disc at upper levels (T12-L1, L1-L2, and L2-L3) showed significant improvement in radicular and back pain, myelopathy, and statistically significant improvement of ODI score following surgery [7].

Our study reported a non-significant association between patient's sex and level of the lumbar disc and surgical outcomes; this was in agreement with Pochon et al. [35].

The retrospective design and the small patient numbers in both groups are considered limitations of this study. Yet, the very low incidence of ULDH is an important factor that limits recruitment of a relatively large number of patients. Furthermore, a longer follow-up is necessary to evaluate any potential complications.

\section{Conclusion}

Both decompression and decompression combined with transpedicular screw fixation had comparable favorable outcomes in patients with ULDH. These included pain, functional outcome, and improvements in muscle power and urinary incontinence. However, addition of pedicle screw fixation did not improve the outcomes of ULDH patients.

\section{Abbreviations}

LDH: Lumbar disc herniation; ULDH: Upper lumbar disc herniation; VAS: Visual analogue score; ODI: Oswestry Disability Index; CSF: Cerebrospinal fluid

\section{Supplementary Information}

The online version contains supplementary material available at https://doi. org/10.1186/s41984-021-00104-2.

\section{Additional file 1.}

\section{Acknowledgements}

We would like to thank the medical statistical unit and Tanta University Hospitals for their great help in data interpretations.

\section{Authors' contributions}

A Y S: participated in the study's idea, design, patients' selection, data interpretation, data collection, statistical analysis, references collection, manuscript writing, revision, and final approval. A A F: participated in the study idea and design, patients' assessment and inclusion, imaging interpretation, statistical analysis, references collection, manuscript writing, and final approval.

Funding

No funding had been received.

Availability of data and materials

The datasets used and/or analyzed during the current study are available from the corresponding author on reasonable request.

\section{Declarations}

Ethics approval and consent to participate

- The manuscript was approved from The Research Ethics Committee and Quality Assurance Unit, Faculty of Medicine, Tanta University.

- The URL: http://tqac.tanta.edu.eg/new-tqac/.

QualityAssuranceUnit@hotmail.com.

- Approval Code: 33919/6/20.

- Name of the PI: Ahmed Youssef Soliman.

- Name of the department: Neurosurgery.

- Type of the research: promotion research.

- Date of approval: June 2020. 
- The study's protocol was approved by The Research Ethics Committee and Quality Assurance Unit, Faculty of Medicine, Tanta University. Participations were voluntary, informed consents were approved by all participants' guardians, and any possible risks were clarified.

\section{Consent for publication}

Not applicable.

\section{Competing interests}

The authors declare that they have no competing interests.

\section{Author details}

${ }^{1}$ Neurosurgery Department, Faculty of Medicine, Tanta University|, Tanta 31527, Egypt. ${ }^{2}$ Neurosurgery Department, Faculty of Medicine, Port Said University, Port Fuad 42511, Egypt.

Received: 29 July 2020 Accepted: 15 April 2021

Published online: 31 May 2021

\section{References}

1. Fardon DF, Williams AL, Dohring EJ, Murtagh FR, Gabriel Rothman SL, Sze GK. Lumbar disc nomenclature: version 2.0: recommendations of the combined task forces of the North American Spine Society, the American Society of Spine Radiology and the American Society of Neuroradiology. Spine J. 2014;14(11):2525-45. https://doi.org/10.1016/j.spinee.2014.04.022.

2. Lee D-S, Park K-S, Park M-S. The comparative analysis of clinical characteristics and surgical results between the upper and lower lumbar disc herniations. J Korean Neurosurg Soc. 2013;54(5):379-83. https://doi. org/10.3340/jkns.2013.54.5.379.

3. Sharifi G, Rahimzadeh A, Fereydonyan N, Divanbeigi A, HJo K. The clinical outcomes of patients with L1-L2 disc herniation treated by microsurgical trans facet approach. J Spine Neurosurg 7: 3. J Spine Neurosurg. 2018;7:2.

4. Iwasaki M, Akino M, Hida K, Yano S, Aoyama T, Saito H, et al. Clinical and radiographic characteristics of upper lumbar disc herniation: ten-year microsurgical experience. Neurol Med Chir (Tokyo). 2011;51(6):423-6. https:// doi.org/10.2176/nmc.51.423.

5. Kim D-S, Lee J-K, Jang J-W, Ko B-S, Lee J-H, Kim S-H. Clinical features and treatments of upper lumbar disc herniations. J Korean Neurosurg Soc. 2010; 48(2):119-24. https://doi.org/10.3340/jkns.2010.48.2.119.

6. Berry JA, Elia C, Saini HS, Miulli DE. A review of lumbar radiculopathy, diagnosis, and treatment. Cureus. 2019;11(10):e5934-e.

7. Toubar AF, El Sawy M. Herniated disc at the upper lumbar region: surgical technique and clinical outcomes \%J Egyptian Spine Journal. Egy Spine J. 2019;30(1):23-30. https://doi.org/10.21608/esj.2019.7149.1086.

8. Dave BR, Degulmadi D, Krishnan A, Mayi S. Risk factors and surgical treatment for recurrent lumbar disc prolapse: a review of the literature. Asian Spine J. 2020;14(1):113-21. https://doi.org/10.31616/asj.2018.0301.

9. Sanderson SP, Houten J, Errico T, Forshaw D, Bauman J, Cooper PR. The unique characteristics of "upper" lumbar disc herniations. Neurosurgery. 2004;55(2):385-9; discussion 9. https://doi.org/10.1227/01.NEU.000012954 8.14898.9B.

10. Wu X-B, Li Z-H, Yang Y-F, Gu X. Two-level percutaneous endoscopic lumbar discectomy for highly migrated upper lumbar disc herniation: a case report. World J Clin Cases. 2020;8(1):168-74. https://doi.org/10.12998/wjcc.v8.i1.168.

11. Elkatatny AAAM, Hamdy TM, Moenes KM. Comparison between results of microdiscectomy and open discectomy in management of high-level lumbar disc prolapse. Open access Macedonian J Med Sci. 2019;7(17):28517. https://doi.org/10.3889/oamjms.2019.679.

12. Baradaran A, Ebrahimzadeh MH, Birjandinejad A, Kachooei AR. Cross-cultural adaptation, validation, and reliability testing of the modified Oswestry disability questionnaire in Persian population with low back pain. Asian Spine J. 2016;10(2):215-9. https://doi.org/10.4184/asj.2016.10.2.215.

13. Karaaslan B, Aslan A, Börcek AÖ, Kaymaz M. Clinical and surgical outcomes of upper lumbar disc herniations: a retrospective study. Turkish J Med Sci. 2017;47(4):1157-60. https://doi.org/10.3906/sag-1604-113.

14. Jha RT, Syed HR, Catalino M, Sandhu FA. Contralateral approach for minimally invasive treatment of upper lumbar intervertebral disc herniation: technical note and case series. World Neurosurg. 2017;100:583-9. https:// doi.org/10.1016/j.wneu.2017.01.059.
15. Elqazaz M. Surgical excision of upper lumbar disc herniations \%」 Egyptian Spine Journal. Egy Spine J. 2015;14(1):46-52. https://doi.org/10.21608/esj.201 5.3955.

16. Ruan W, Feng F, Liu Z, Xie J, Cai L, Ping A. Comparison of percutaneous endoscopic lumbar discectomy versus open lumbar microdiscectomy for lumbar disc herniation: a meta-analysis. Int J Surg (London). 2016;31:86-92.

17. Schroeder GD, Guyre CA, Vaccaro AR, editors. The epidemiology and pathophysiology of lumbar disc herniations. Semin Spine Surg. 2016;28(1):2-

18. Kido T, Okuyama K, Chiba M, Sasaki H, Seki N, Kamo K, et al. Clinical diagnosis of upper lumbar disc herniation: pain and/or numbness distribution are more useful for appropriate level diagnosis. J Orthop Sci. 2016;21(4):419-24. https://doi.org/10.1016/j.jos.2016.03.003.

19. Kapetanakis S, Chaniotakis C, Kazakos C, Papathanasiou JV. Cauda equina syndrome due to lumbar disc herniation: a review of literature. Folia Med. 2017;59(4):377-86. https://doi.org/10.1515/folmed-2017-0038.

20. Toubar AF, El Sawy MJESJ. Herniated disc at the upper lumbar region: surgical technique and clinical outcomes. Egy Spine J. 2019;30(1):23-30. https://doi.org/10.21608/esj.2019.7149.1086.

21. Lee SH, SJJoKNS C. L1-2 disc herniations: clinical characteristics and surgical results. J Korean Neurosurg Soc. 38(3):196-201.

22. Omidi-Kashani F, Hejrati H, Ariamanesh S. Ten important tips in treating a patient with lumbar disc herniation. Asian Spine J. 2016;10(5):955-63. https://doi.org/10.4184/asj.2016.10.5.955.

23. Tacconi L. Lumbar discectomy: has it got any ill-effects? J Spine Surg (Hong Kong). 2018;4(3):677-80. https://doi.org/10.21037/jss.2018.07.05.

24. Satoskar SR, Goel AA, Mehta PH, Goel A. Quantitative morphometric analysis of the lumbar vertebral facets and evaluation of feasibility of lumbar spinal nerve root and spinal canal decompression using the Goel intraarticular facetal spacer distraction technique: a lumbar/cervical facet comparison. J Craniovertebral Junction Spine. 2014;5(4):157-62. https://doi.org/10.4103/ 0974-8237.147079.

25. Butler AJ, Alam M, Wiley K, Ghasem A, Rush lii AJ, Wang JC. Endoscopic lumbar surgery: the state of the art in 2019. Neurospine. 2019;16(1):15-23. https://doi.org/10.14245/ns.1938040.020.

26. Apostolides PJ, Jacobowitz R, Sonntag VK. Lumbar discectomy microdiscectomy: "the gold standard". Clin Neurosurg. 1996;43:228-38.

27. Sørlie A, Gulati S, Giannadakis C, Carlsen SM, Salvesen $\varnothing$, Nygaard ØP, et al. Open discectomy vs microdiscectomy for lumbar disc herniation - a protocol for a pragmatic comparative effectiveness study. F1000Res. 2016;5:2170.

28. Chirchiglia D, Chirchiglia P, Murrone DJCNJ. Postural instability after lumbar spinal surgery: are there any predictive factors? A case control study. Chinese Neurosurg J. 2018;4(1):40. https://doi.org/10.1186/s41016-018-0147-2.

29. Benz RJ, Garfin SR. Current techniques of decompression of the lumbar spine. Clin Orthop Relat Res. 2001;384:75-81. https://doi.org/10.1097/00003 086-200103000-00010.

30. Kim HJ, Bak KH, Chun HJ, Oh SJ, Kang TH, Yang MS. Posterior interspinous fusion device for one-level fusion in degenerative lumbar spine disease: comparison with pedicle screw fixation - preliminary report of at least one year follow up. J Korean Neurosurg Soc. 2012;52(4):359-64. https://doi.org/1 0.3340/jkns.2012.52.4.359

31. Lin T-Y, Wang Y-C, Chang C-W, Wong C-B, Cheng Y-H, Fu T-S. Surgical outcomes for upper lumbar disc herniation: decompression alone versus fusion surgery. J Clin Med. 2019;8(9):1435. https://doi.org/10.3390/jcm8091435.

32. Ido K, Shimizu K, Tada H, Matsuda Y, Shikata J, Nakamura T. Considerations for surgical treatment of patients with upper lumbar disc herniations. J Spinal Disord. 1998;11(1):75-9.

33. Katz JN, Lipson SJ, Lew RA, Grobler LJ, Weinstein JN, Brick GW, et al. Lumbar laminectomy alone or with instrumented or noninstrumented arthrodesis in degenerative lumbar spinal stenosis: patient selection, costs, and surgical outcomes. Spine. 1997;22(10):1123-31.

34. Epstein NE. Adjacent level disease following lumbar spine surgery: a review. Surg Neurol Int. 2015;6(Suppl 24):S591-S9. https://doi.org/10.4103/21527806.170432.

35. Pochon $L$, Kleinstück FS, Porchet F, Mannion AF. Influence of gender on patient-oriented outcomes in spine surgery. Eur Spine J. 2016;25(1):235-46. https://doi.org/10.1007/s00586-015-4062-3.

\section{Publisher's Note}

Springer Nature remains neutral with regard to jurisdictional claims in published maps and institutional affiliations. 